\title{
Por uma nova didática: discursos e narrativas no Ensino Superior
}

\author{
For a new didactic: discourses and narratives in
}

Higher Education

Por una nueva didáctica: discursos y narrativas en la

Educación Superior

Marcelo Siqueira Maia Vinagre Mocarzel (iDa

MARY RANGEL (D)

\section{Resumo}

Este artigo reúne experiências realizadas em uma instituição de ensino superior confessional, localizada no estado do Rio de Janeiro, Brasil. A partir de convênio firmado com o Google para Educação, novas abordagens didáticas foram sugeridas aos professores de todos os cursos, objetivando uma maior qualificação das aulas e um maior interesse dos estudantes. Os docentes foram apresentados ao conceito de metodologias ativas, ferramentas que buscam dinamizar as aulas e tornar mais significativo o aprendizado dos estudantes. As falas de alunos de uma turma da disciplina Didática, oferecida aos cursos de História e Pedagogia, sobre as aulas, sobre as metodologias ativas e o uso de tecnologias Google, foram interpretadas com uso da Análise de Discurso. As falas foram coletadas na avaliação do curso e retratam, em certa medida, que muitos dos objetivos traçados, pela instituição quando da proposta do uso de metodologias ativas de aprendizagem e ferramentas tecnológicas e pelo docente responsável quanto à sequência de ações didáticas, foram alcançados, e alguns deles até superados.

Palavras-chave: Ensino Superior. Metodologias ativas da aprendizagem. Ferramentas tecnológicas. Análise de discurso.

\footnotetext{
a Universidade Católica de Petrópolis, Petrópolis, RJ, Brasil; Centro Universitário La Salle do Rio de Janeiro, Niterói, RJ, Brasil. Universidade Estácio de Sá, Rio de Janeiro, RJ, Brasil. Doutor em Comunicação, e-mail: marcelomocarzel@gmail.com

b Universidade Federal Fluminense, Niterói, RJ, Brasil; Universidade do Estado do Rio de Janeiro, Rio de Janeiro, RJ, Brasil; Centro Universitário La Salle do Rio de Janeiro, Niterói, RJ, Brasil. Doutora em Educação, e-mail: mary.rangel@lasalle.org.br
} 


\begin{abstract}
This article brings together experiences at a religious institution of higher education, located in the state of Rio de Janeiro, Brazil. Based on an agreement signed with Google for Education, new didactic approaches were suggested to professors of all courses, seeking for a better qualification of the classes and greater student interest. Professors were introduced to the concept of active methodologies, tools that seek to dynamize classes and make learning more meaningful to students. The speeches of students of a Didactic class, offered to the courses of History and Pedagogy, were interpreted using Discourse Analysis, about the classes, about the active methodologies and about the use of Google technologies. The speeches were collected in the evaluation of the course and portray to a certain extent that many of the objectives set by the institution, when the proposal of the use of active learning methodologies and technological tools and by the teacher responsible, the sequence of didactic actions were achieved, and some of them even surpassed.
\end{abstract}

Keywords: Higher Education. Active learning methodologies. Technological tools. Discourse analysis.

\title{
Resumen
}

Este artículo reúne experiencias realizadas en una institución de enseñanza superior confesional, ubicada en el estado de Río de Janeiro, Brasil. A partir de un convenio firmado con Google para Educación, nuevos enfoques didácticos fueron sugeridos a los profesores de todos los cursos, con el objetivo de una mayor calificación de las clases y un mayor interés de los estudiantes. Los docentes fueron presentados al concepto de metodologías activas, herramientas que buscan dinamizar las clases y hacer más significativo el aprendizaje de los estudiantes. Las palabras de alumnos de una clase de la disciplina Didáctica, ofrecida a los cursos de Historia y Pedagogía, fueron interpretadas con el uso del Análisis de Discurso, sobre las clases, sobre las metodologías activas y el uso de tecnologías Google. Las palabras se recogieron en la evaluación del curso y retrata en cierta medida que muchos de los objetivos trazados por la institución, en la propuesta del uso de metodologías activas de aprendizaje y herramientas tecnológicas y por el docente responsable, la secuencia de acciones didácticas, y algunas de ellas hasta superadas.

Palabras clave: Enseñanza Superior. Metodologías activas del aprendizaje. Herramientas tecnológicas. Análisis de discurso.

\section{Introdução}

A didática, como área de estudos do campo educacional, tem sido objetivo de inúmeros debates, relacionando-se, sobretudo, com a ação de alunos e professores. De acordo com Penin (2002, p. 33), “é inevitável o repensar contínuo da educação, do homem, da escola e, por conseguinte, da didática”. Desse modo, 
nos tempos que Santos (2009) classifica como de transição paradigmática, necessitamos repensar a didática e seus pressupostos.

De acordo com as ideias de Sacristán e Pérez Gómez (2007), a didática pode ser entendida como a ciência, arte e práxis do ensino-aprendizagem, apontando para três vertentes importantes:

uma teoria científica que a baseia (no caso, seus principais alicerces são as teorias da aprendizagem), uma atividade de apropriação quase "artística", feita por seus praticantes, que a transformam de acordo com seus talentos e possibilidades, e uma categoria de análise, pesquisa e reflexão, que é testada e avaliada quando colocada em prática (MOCARZEL; RANGEL, 2018, p. 2339-2340)

Este trabalho teve por objetivo analisar discursos sobre experiências realizadas em uma instituição de ensino superior confessional, situada no estado do Rio de Janeiro, Brasil. A instituição firmou convênio com o Google para Educação, possibilitando novas abordagens didáticas a partir do acesso à tecnologia. Foram introduzidas as metodologias ativas da aprendizagem, ferramentas que buscam dinamizar as aulas e tornar mais significativo o aprendizado dos estudantes e mais dinâmica a tarefa do professor.

Fizemos uso da Análise de Discurso, como método e metodologia de pesquisa, da Análise de Discurso, campo do conhecimento cujo fundador é o francês Michel Pêcheux (1938-1983). Segundo Orlandi (2010), este método supera a Linguística, ainda que dependa dela para existir, conjugando a língua com a história na produção de sentidos. Segundo Pêcheux (2011), o discurso depende do sujeito e não há sujeito sem ideologia. Logo, a materialidade específica da ideologia se converte em discurso e a materialidade específica do discurso é a própria língua. Foram coletadas seis falas de alunos de uma turma da disciplina Didática, oferecida aos cursos de História e Pedagogia, com as falas anônimas dos estudantes sobre as aulas, sobre as metodologias ativas e o uso de tecnologias Google.

\section{Uma nova didática para novos tempos}

Um dos principais fenômenos das últimas décadas é o expansionismo tecnológico, que reorganizou relações em um novo quadro social para as economias 
capitalistas. Percebemos que a instituição educacional se modificou, bem como suas funções e seus propósitos. Pérez Gómez (2001, p. 261) aponta "três funções complementares que a escola pode e deve exercer: a função socializadora, a função instrutiva e a função educativa". As instituições de Ensino Superior, apesar das diferenças, guardam estrita relação com as funções apontadas. A primeira está relacionada aos influxos de socialização que a instituição exerce nas novas gerações, condicionando "suas formas de pensar, sentir, expressar-se e atuar" (PÉREZ GÓMEZ, 2001, p. 262).

Ou seja, ela é responsável por promover trocas sociais, interações entre indivíduos, entre grupos e entre indivíduo e grupo. Em algumas sociedades este lócus se dá em outras instituições, como espaços religiosos, culturais e políticos, mas a reorganização da estrutura familiar, com as mulheres participando ativamente do mercado de trabalho e a crescente laicização da sociedade ocidental colocaram a escola como espaço prioritário da socialização.

A função instrutiva é a mais evidente: a instituição educacional precisa debruçar-se sobre o processo de ensino-aprendizagem para preparar as novas gerações para a incorporação no mundo de trabalho, aperfeiçoando o processo espontâneo de socialização. Aqui reside um desafio ligado à didática: como instruir todos, ao mesmo tempo, no mesmo ritmo? Esse é um problema epistemológico que vem sendo tratado pela disciplina nos últimos anos e que ganha novas respostas na medida em que as tecnologias da informação e comunicação avançam.

Por fim, temos a função educativa, que para o autor significa "oferecer às futuras gerações a possibilidade de questionar a validade antropológica daqueles influxos sociais, de elaborar alternativas e de tomar decisões relativamente autônomas" (PÉREZ GÓMEZ, 2001, p. 263). A ideia desta função é a reconstrução do pensamento: o indivíduo deve ser capaz, através dos processos educacionais, de refletir criticamente sobre sua própria existência e sobre as relações que o cercam.

Às instituições de Ensino Superior, poderíamos acrescentar uma quarta função, não proposta por Pérez Gómez: a função heurística. Espera-se que a universidade seja um templo da inovação, da pesquisa científica, do avanço tecnológico. Nem sempre é assim, em uma realidade em que poucos países 
concentram quase toda a produção científica do mundo, muitas instituições não incorporam esta tarefa, que já é muito restrita à pós-graduação. O saber científico e seus códigos continuam, assim, a alcançar uma tímida parcela dos estudantes. Mas o saber comum é ainda mais negligenciado. E aí entra o professor.

O papel do professor, na nova didática, é organizar os diversos centros de irradiação de conhecimento e atribuir-lhes prioridades (mas sem julgamento de valor). A classificação só reforça o modelo antiquado de valorização de conhecimentos considerados mais importantes e o desprestígio do conhecimento comum. Todo conhecimento importa, ao menos para quem o produz. Portanto, é preciso que o professor seja um articulador de conhecimentos, fazendo uma espécie de curadoria do que pode e deve ser trabalhado em cada momento.

A nova didática não deve — e não pode — se limitar aos conteúdos científicos; é preciso levar os debates do senso comum para as salas de aula. Ensinar não pode mais se resumir à transmissão, uma vez que que a detenção do saber não é mais centrada na figura do professor: o conhecimento é "caósmico", tomando emprestado o termo de Santos (2009, p. 288). Não há um centro cósmico de irradiação: ele está em todo lugar, com múltiplos vetores.

Zabala (2010) levanta três novos tipos de conteúdos que devem orientar o ensino e a aprendizagem: os conteúdos factuais ou conceituais, que tratam dos saberes disciplinares; os conteúdos procedimentais, que levam em conta o fazer, os procedimentos que o aluno deverá ser capaz de desenvolver para aprender determinada coisa; e os conteúdos atitudinais, relacionados à convivência, à formação do indivíduo, à apropriação de valores. A partir desta nova formatação, ancorada em um modelo de construção do conhecimento, podemos enxergar como os saberes em si não são o objeto fundamental da didática, mas sim tudo que com eles se relaciona: os hábitos adquiridos, os métodos e técnicas de compreensão, as atitudes demonstradas durante o processo etc.

Tanto o planejamento como o currículo precisam se realinhar com uma nova perspectiva didática para promover uma nova educação. É essencial que o currículo privilegie competências e habilidades, ou seja, tenha nas inteligências múltiplas (GARDNER, 1985) seu principal plano de ação, mas sem deixar de lado uma visão integrada da realidade. Mas estabelecer competências não significa deixar de lado os 
objetivos maiores da formação humana. "É preciso evitar a ideia de que tudo tem a mesma relevância e, ainda pior, que as pessoas se percam na definição de miríades de competências ou de objetivos e se deixem submergir numa atomização e fragmentação do currículo" (FERNANDES, 2009, p. 90).

É preciso, então, repensar a avaliação a partir de uma nova didática. A avaliação, como instrumento e como disciplina, tem sido um dos terrenos mais instáveis do campo educacional, porque não há uma receita para se avaliar bem. Sendo assim, avaliar é uma tarefa artesanal e constituir um modelo perfeito é algo utópico. Fernandes (2013) nos mostra que a avaliação não é mera técnica e que o modelo formativo precisa se sobrepor ao somativo. A avaliação precisa ajudar a "motivar os alunos para aprenderem com compreensão e para lhes dar conta de seus progressos e de seus sucessos, mas também de seus insucessos e dificuldades" (FERNANDES, 2013, p. 93).

A avaliação formativa dialoga com a nova didática, na medida em que cumpre o papel de fornecer "feedback" (FERNANDES, 2013, p. 74) da aprendizagem ao aluno e ao professor. Enquanto a avaliação somativa busca classificar ao fim de uma etapa, definindo quem é capaz de aprender e quem não é, hierarquizando os alunos e os saberes, a avaliação formativa deve ocorrer ao longo de todo o processo de ensino-aprendizagem, conduzindo de forma dialógica o aluno ao questionamento e desenvolvendo sua autoestima em relação ao ato de aprender. Assim, a didática precisa dar conta de três dimensões apontadas por Candau (2013): a técnica, a humana e a política.

Nesta perspectiva,

a reflexão didática parte do compromisso com a transformação social, com a busca de práticas pedagógicas que tornem o ensino de fato eficiente (não se deve ter medo da palavra) para a maioria da população. Ensaia. Analisa. Experimenta. Rompe com uma prática profissional individualista. Promove o trabalho em comum de professores e especialistas. Busca as formas de aumentar a permanência das crianças na escola. Discute a questão do currículo em sua interação com uma população concreta e suas exigências, etc. (CANDAU, 2013, p. 24).

Essas e outras questões são latentes para o desenvolvimento educacional das instituições educacionais, que precisam se alinhar às demandas contemporâneas, sem perder a humanidade de suas funções sociais primárias. A seguir, buscaremos 
evidenciar como essa nova didática foi repensada na instituição estudada e como os alunos — os principais interessados — reagiram a essas mudanças em seus discursos.

\section{Fundamentos das metodologias ativas de aprendizagem}

A proposta de metodologias ativas de aprendizagem se destaca pelo incentivo ao engajamento dos alunos e pela importância dada aos processos que estimulem a reflexão, a autoria e a produção criativa dos mesmos. Diferentemente das metodologias tradicionais, que se limitam à exposição de conteúdos, ainda que fazendo uso das Tecnologias da Informação e Comunicação (TIC), as metodologias ativas trabalham com um aluno que não é apenas ouvinte, mas parte do processo criador do processo de ensino-aprendizagem. (RANGEL, 2010).

O pensamento de Sartre (2002, p. 391) é significativo ao intuito de caracterizar o conhecimento como processo pessoal: “[...] só há conhecimento de um ponto de vista”. Essa ideia é complementada pelo princípio de que há uma relação intrínseca entre o conhecimento e o sujeito, que assume uma atitude comprometida e engajada. A consideração a esse princípio recomenda também a atenção ao sentimento, às expectativas dos alunos, de modo que as práticas e atividades de ensino-aprendizagem correspondam ao seu interesse e potencial de realização.

O grande objetivo do uso de metodologias ativas é voltar os esforços didáticos para a aprendizagem, e não apenas para o ensino, como sempre ocorreu. Partia-se da ideia de que uma boa aula, bem planejada, com um professor bem preparado derivava necessariamente em aprendizagem e só não aprendia que não se dedicasse a contento. A culpabilização do aluno - e às vezes até da família e de suas condições sociais — marcava a educação. Comumente, professores cujas disciplinas possuíam altos índices de reprovação eram considerados rigorosos e competentes e os alunos que ficavam pelo caminho representavam apenas um fluxo natural.

Contrariando esta lógica, a instituição de Ensino Superior pesquisada propôs uma nova abordagem para as aulas de todos os professores, de todas as áreas do conhecimento e cursos. As aulas deveriam, a partir daquele momento, ser centradas na aprendizagem e não mais no ensino. Se o professor ensinava de determinada maneira e os alunos não aprendiam, caberia ao professor buscar novas maneiras. Se 
essa relação fosse direta, consistiria apenas em mudar o eixo de culpabilização: agora, seria o professor o culpado pelo fracasso ou sucesso dos estudantes, algo tão ou mais injusto do que o que ocorria antes.

Para evitar essa dicotomia, a instituição investiu muitos recursos em formação e inovação tecnológica. Firmou um contrato de grande vulto com o Google para Educação, abrindo aos docentes e discentes um leque de ferramentas educacionais a serem utilizadas dentro e fora de sala de aula. Paralelamente, investiu maciçamente em formação continuada, para que os docentes soubessem utilizar as ferramentas com qualidade e pudessem adequar suas aulas, seu planejamento, suas formas de avaliação à nova didática que se desenhava.

Dentre um vasto cardápio de metodologias ativas da aprendizagem apresentadas, três foram escolhidas para que se iniciasse o aprofundamento dos docentes e para que estes pudessem aplicar em suas aulas após o período de formação: flipped classroom ou sala de aula invertida (BERGMANN; SAMS, 2018), peer instruction ou instrução por pares (MAZUR, 1997) e webquest ou busca virtual (DODGE, 1995).

A sala de aula invertida consiste em um método de trabalho que troca o aluno e o professor de posição. No modelo escolar tradicional, o professor prepara a aula e expõe aos estudantes, que ouvem e buscam assimilar o que foi dito. Antes da aula, eles nada sabem sobre seu teor e cabe ao docente todo o trabalho de planejamento didático. Bergmann e Sams (2018, p. 11) afirmam que, na sala de aula invertida, "o que tradicionalmente é feito em sala de aula, agora é executado em casa e o que tradicionalmente é feito como trabalho de casa, agora é realizado em sala de aula".

Ou seja, com o uso dessa metodologia ativa, o aluno estuda o conteúdo em casa previamente (seja por um livro, artigo ou mesmo um vídeo, recurso muito utilizado) e chega em sala com uma noção do tema da aula. A metodologia sugere que eles utilizem o método Cornell de estudo, desenvolvido entre os anos $1940 \mathrm{e}$ 1950 na universidade norte-americana de mesmo nome, que consiste em transcrever os pontos mais importantes, registrar todas as dúvidas e resumirem o conteúdo aprendido. Assim, ao começar a aula, há uma rápida síntese do que foi aprendido em casa e um momento para esclarecimento de dúvidas suscitadas pelos estudantes. 
Após essa introdução, o professor distribui as tarefas do dia e fica atento às dúvidas que venham a surgir.

Com a ferramenta Google Classroom, a sala de aula invertida é potencializada, uma vez que se cria o ambiente ideal para a postagem de conteúdos e acompanhamento daqueles que tiveram acesso ao mesmo. Assim, há uma integração positiva entre a tecnologia e metodologia ativa em questão, que poderia ser utilizada sem o suporte tecnológico, porém demandando mais recursos (impressão de textos, compra de livros) e com uma possibilidade de feedback reduzida, pois o acompanhamento por parte do professor teria que se dar de maneira individual e não grupal, como o Google Classroom permite.

A segunda metodologia apresentada aos docentes foi a instrução por pares, criada pelo professor de física de Harvard, Eric Mazur, nos anos 1990. Entendemos que ela vai além, no sentido de propiciar um ambiente de interação entre os estudantes, algo que muitas vezes se restringe aos aspectos sociais. Trata-se de uma abordagem pedagógica baseada em testes conceituais (MAZUR, 1997), formulários com perguntas e respostas em múltipla escolha. A pergunta é a chave da aprendizagem por pares, pois conduz as ações decorrentes. Ela é apresentada pelo professor e é dado um tempo para que os alunos reflitam sobre a mesma e depois, registrem, individualmente, suas respostas.

Até aí, trata-se de um modelo meramente tradicional de perguntas e respostas. Mas o aspecto colaborativo se dá nas etapas seguintes: primeiramente, os estudantes se organizam em pares e discutem sobre suas respostas, para, depois, relatarem à turma e ao professor. Este relato pode ser oral, escrito, através de cartões de votação (flashcards) ou mesmo transmitido com algum suporte tecnológico. O professor então analisa quantitativamente as respostas, criando gráficos com os percentuais das respostas apresentadas. Somente após essa compilação de dados é que o professor apresenta a resposta correta e explica o porquê da mesma (MAZUR, 1997).

Nessa ferramenta, o aluno tem diversas chances de refletir sobre a sua resposta: primeiro individualmente, depois em pares, por fim com toda a turma. Trata-se, portanto, de um conhecimento trabalhado em diversas camadas, aprofundado, que vai se refinando, não algo que o estudante responde 
apressadamente e entrega de qualquer jeito. A ferramenta Google Forms é um grande aliado das práticas de instrução por pares, pois ela permite que as votações sejam feitas em tempo real, com o cálculo e construção dos gráficos, fazendo com que o apelo visual para a turma seja ainda maior.

A busca virtual foi a terceira metodologia ativa apresentada. Como o próprio nome já diz, ela requer o ambiente virtual para que aconteça, portanto é a metodologia ativa mais afeita às tecnologias da informação e comunicação. A internet é o campo de exploração dessa busca pelo conhecimento. Segundo Dodge (1995), para que a webquest proposta seja bem-sucedida, é preciso apresentar aos estudantes uma tarefa factível e interessante, não tão difícil que não possa ser resolvida, nem tão fácil que possibilite a queima de etapas.

Cabe ao professor elaborar um guia para a busca, que forneça algumas informações de fundo e um conjunto de fontes iniciais que direcionem a pesquisa, impedindo que os trabalhos sejam baseados em materiais não confiáveis. A busca na web não se restringe às pesquisas no Google - ainda que sejam de vital importância e recorrentes. Pode-se propor entrevistas com pessoas via e-mail ou videoconferência (a plataforma oferece o Gmail e o Google Hangouts como opções), palestras em tempo real no Youtube ou em outros suportes, leitura de livros no Google Books etc.

Cabe ao professor elencar os pontos essenciais do roteiro, em passos claros e funcionais. Dodge (1995) sugere o uso de questões orientadoras, mapas conceituais e cronogramas como elementos de suporte aos estudantes. Após o trabalho de busca, tendo encontrado o que se procura, os estudantes devem formalizar uma síntese da pesquisa, o que pode incluir textos, apresentações, planilhas, vídeos etc. Outro diferencial, apesar de não ser uma condição, é que a busca virtual possibilita os trabalhos em grupo, não apenas em pares ou individuais.

\section{Os discursos dos estudantes sobre o uso das metodologias ativas e tecnologia}

Segundo Orlandi (2010, p. 17), a Análise de Discurso considera que a linguagem não é transparente, portanto, “ela não procura atravessar o texto para 
encontrar um sentido do outro lado". Analisaremos abaixo seis sequências discursivas (SD), coletadas entre 48, que trazem uma visão representativa dos pontos positivos e negativos das aulas com nova abordagem. Cabe lembrar que a escolha dos registros é também um discurso, mas as limitações práticas, como o limite de caracteres do artigo, nos impossibilitam de utilizar todas.

SD1: Eu gostei das aulas, achei que elas me forçaram a ler o texto, ainda mais porque não fica tudo mastigadinho... tem que ralar, correr atrás, se não fica para trás, 0 pessoal de História é muito preparado né... (Aluna de Pedagogia 1)

A primeira sequência em destaque traz algumas informações relevantes à pesquisa. Inicialmente, a aluna utiliza o pronome pessoal "Eu", para marcar que aquela fala diz respeito a ela e a ninguém mais. Ela não está representando ninguém, assim possibilita que qualquer discordância seja compreendida pelo leitor. $\mathrm{O}$ uso do verbo "forçar" traz uma carga ambígua, pois forçar alguém a fazer algo é normalmente tido como algo negativo. Neste caso, há um deslocamento de sentido, e forçar poderia ser entendido como algo positivo, já que o modelo da aula a compeliu a ler os textos, uma condição necessária para a aprendizagem dos conteúdos.

$\mathrm{Na}$ mesma sequência, ela fez uma crítica a conteúdos muito sintéticos, chamados de "mastigadinhos". O sufixo "inho", que traz o diminutivo, pode se referir a algo carinhoso, mas também a algo menor, de menor prestígio e importância, que é o caso da resposta. Há uma crítica a conteúdos muito rasos, que não levariam à reflexão: isso é comprovado pela continuação, em que ela afirma que é preciso "ralar", correr atrás", gírias que indicam esforço, disciplina, estudo. Por fim, ela faz uma comparação, posicionando-se enquanto sujeito do discurso. Ao elogiar "o pessoal de História", chamando os alunos desse curso de muito preparados, ela se coloca, simultaneamente, de uma maneira inferiorizada na origem, mas que se equipara pelos esforços.

Há aí um debate sobre capital cultural e poder simbólico, sobre formação inicial, sobre o perfil do aluno de História frente ao de Pedagogia, esses normalmente egressos das camadas mais pobres da população. Não é nosso objetivo entrar nesse debate sociológico, mas vale a pena destacar que o conhecimento continua sendo uma forma de distinção, sobretudo nos meios 
acadêmicos, como Bourdieu (2013) apontava, e o uso de metodologias ativas pode possibilitar novas relações e hierarquias entre pessoas com capitais sociais distintos.

Do ponto de vista didático, a SD1 corrobora com a visão de Bergmann e Sams (2018, p. 19) de que "a inversão ajuda os estudantes ocupados" e ao mesmo tempo cria um objetivo para a leitura, pois sem ela não haverá compreensão do conteúdo. No modelo tradicional, passivo, o aluno sabe que haverá a exposição do professor, por isso, ler o texto ou ver o vídeo em casa torna-se algo opcional. Se ele conseguir entender o conteúdo durante a explanação, há uma visão de que não é necessário mais fixar o que foi aprendido.

SD2: Sempre tive uma dificuldade enorme em pesquisar. Acho que não sei formular a pergunta, sabe... eu gostei das aulas e o Google ajuda muito. Aprender a saber perguntar ao Google foi o que mais amei. Com 21 anos eu não sabia que existia Google Acadêmico! (Aluna de História 1)

A segunda sequência traz um relato pessoal da aluna, que se mescla com a avaliação da disciplina Didática e do próprio método. Em seu depoimento, ela afirma que tinha dificuldades em realizar pesquisas, por não saber formular questões. Sobretudo nas pesquisas virtuais, saber formular a pergunta e escolher as palavras-chave é essencial para se obter resultados apurados. Ao dizer que "Aprender a saber perguntar ao Google foi o que mais amei.", a estudante responde positivamente à tentativa da instituição de divulgar conhecimentos sobre as tecnologias da informação e comunicação (no caso as ferramentas Google) e de articulá-las com as metodologias ativas.

As orientações trazidas por Dodge (1995) para a aplicação de uma busca virtual indicam que o docente deve elaborar um guia para a busca, não permitindo que o aluno se perca e se afaste do objetivo da tarefa. Sendo assim, o relato indica que as orientações planejadas contribuíram para a formação do pensamento autônomo da estudante. A ideia de autonomia do pensamento, tão discutida por pensadores como Freire (1996), Sacristán e Pérez Gómez (2007) e outros se materializou no discurso da aluna de História, sobretudo quando ela exemplifica o caráter heurístico das metodologias, que lhe possibilitou descobrir uma nova forma de pesquisar aos 21 anos.

SD3: Quando o professor começa a falar, fica tudo embaralhado na minha cabeça, me dá sono, quero mexer no celular... mas se estou ocupado, trabalhando, resolvendo uma coisa, eu fico focado. (Aluno de História 2) 
O terceiro relato traz uma crítica ao modelo tradicional de escola e ao que Sacristán e Pérez Gómez (2007) chamariam de enfoque enciclopédico do ensino. A escola como local de treinamento e condicionamento faz uso da passividade do discente, que deve se adequar para armazenar e reproduzir aquilo que lhe é dito. Ao dizer que "tudo fica embaralhado", que sente "sono" e vontade de "mexer no celular", o estudante aponta os problemas reais que as metodologias ativas buscam enfrentar: o ambiente tedioso da sala de aula regular.

O condicional "se" traz uma série de alternativas, soluções a esse modelo: o aluno quer trabalhar, resolver tarefas para manter-se focado. Seu discurso aponta que há desejo de participar da aula, de aprender, mas que é preciso haver um ambiente convidativo para tal. A sala de aula invertida "fala a língua dos estudantes de hoje", diriam Bergmann e Sams (2018, p. 18). Isso quer dizer que o modelo ativo dialoga com a forma de pensar e agir das novas gerações, acostumadas a buscarem na Internet tudo o que necessitam saber.

SD4: Achei que iríamos mexer muito mais com a tecnologia, isso é um ponto que deixou a desejar. Mas as aulas foram interessantes, mesmo aquelas em que tínhamos que nos colocar e poucos tinham lido o texto. O professor sabia tirar da gente as discussões. (Aluno de História 3)

A SD4 traz duas críticas à condução da disciplina, que podem ser analisadas sob dois prismas. Primeiramente, o fato de a tecnologia não estar presente em todas as aulas: "Achei que iríamos mexer mais...". Isso é algo que precisa ser revisto e repensado, ainda que este discurso não reflita a avaliação da maioria. As metodologias ativas são roupagens novas dadas a práticas antigas, algumas delas milenares. A sala de aula invertida, por exemplo, remete ao método socrático utilizado no período helenístico, em que o diálogo era o fio condutor das descobertas. Mesmo em períodos mais recentes, como nos anos 1920, o curso de Direito de Harvard já fazia uso de estudos de caso, algo que se assemelha em grande medida aos webquests, como o próprio Dodge (1995) aponta. Outro exemplo é método de alfabetização freiriano (FREIRE, 1996), idealizado nos anos 1950 e 1960 e celebrado em todo o mundo, justamente por partir do conhecimento de mundo do aluno e não inicialmente impor conhecimentos estranhos àquela realidade. 
A segunda crítica trata da falta de leitura de alguns estudantes, mesmo que com o incentivo para tal. $\mathrm{O}$ ato de ler é importante para qualquer cidadão, mas para o professor é condição para sua formação intelectual. $\mathrm{O}$ aluno aponta que muitos colegas deixaram de ler alguns textos. O ponto positivo é que o professor não permitiu que a passividade escamoteasse esse problema: os alunos foram instados a participar, a dialogar, ainda que partindo de um lugar de fala diferente do esperado. Assim, há um incentivo para que nas aulas seguintes, os textos sejam lidos e sirvam de ponto de partida para o diálogo.

SD5: A aula em que fomos para a sala Google foi incrível. Vi todo mundo trabalhando nas mesas, com os computadores, pesquisando, procurando respostas... aquilo ali era uma grande empresa cheia de profissionais trabalhando! (Aluna de História 4)

Há um tom bastante elogioso na SD5, que demonstra empolgação com a atividade de busca virtual realizada no ambiente Google. O adjetivo "incrível” demonstra que trata-se de algo pouco comum, ainda que as salas sejam abertas e de livre uso por todos os professores. A instituição, portanto, deve continuar fomentando o uso dos espaços tecnológicos, pois ainda não se tornou um hábito dos docentes. Na continuação, a estudante de História faz uso de uma metáfora, uma comparação implícita e simbólica: “aquilo ali era uma grande empresa cheia de profissionais trabalhando!"

A figura de linguagem escolhida remeteu ao imaginário da aluna, que se viu dentro de uma grande empresa, com estações de trabalho, cada um fazendo algo diferente. Trata-se, em nossa interpretação, de um elogio para o funcionamento das metodologias ativas, que têm como base o que Rangel (2010) aponta: processos que os estimulem à reflexão e à produção criativa e crítica do conhecimento. Assim, o fato de cada um estar fazendo algo diferente rompe com o modelo igualitarista da escola tradicional, em que todos devem estar fazendo a mesma coisa ao mesmo tempo, a lógica de controle do pensamento e da ação. A figura da empresa, apesar de não muito simpática nos meios educacionais, nos remete às companhias de tecnologia criativa, no modelo Vale do Silício, em que cada um realiza suas tarefas da maneira que bem entender, visando à produtividade, tal como o próprio Google. A ideia dos pares de trabalho — e mesmo dos grupos — é algo que Mazur (1997) nomeia como aprendizagem colaborativa. 
SD6: Nunca pensei que fosse gostar tanto de uma aula com tantos textos. Aprendi muito e tenho certeza que a turma toda é dessa opinião. Foi a aula em que mais li e em que mais me diverti, porque era dinâmica. (Aluna de Pedagogia 2)

Encerrando, a SD6 traz um eloquente elogio sobre a disciplina. Segundo a estudante de Pedagogia, o fato de a ementa conter muitos textos traria a ela uma rejeição natural. Porém, com o uso das metodologias ativas, aquilo não só não a desagradou, como a fez gostar muito da aula. Expressões da sequência como "gostar tanto", “Aprendi muito”, “aula em que mais li”, “era dinâmica” corroboram o sentido de envolvimento buscado pelas metodologias ativas.

Ao falar de divertimento, a aluna demonstra que a aprendizagem despertou, inclusive, as estruturas cerebrais ligadas ao prazer, algo que Gardner (1985) aponta como extremamente significativo para o desenvolvimento das inteligências. $O$ discurso traz ainda uma representação do todo, quando a aluna se coloca como porta-voz da turma, falando por si e pelos demais, diferentemente do que fez a aluna da SD1. Ainda que não seja a realidade objetiva, o discurso ganha força enquanto representação de mais de um sujeito em torno daquele sentido objetivado.

\section{Considerações Finais}

Diante dos discursos produzidos e ora analisados, nota-se que as metodologias ativas possibilitaram aproximações, mediadas pelas TIC, dos atos de ensinar e aprender. Os discentes relatam que houve mais interação, possibilitando assim uma interação mais dialógica.. De acordo com Bottentuit Junior, Lisboa e Coutinho (2011, p. 19), os aplicativos Google "permitem aos seus utilizadores o desenvolvimento de várias competências em diferentes níveis tais como: a escrita online (pessoal ou colaborativa), o estímulo visual através de imagens e por fim o auditivo através da gravação e reprodução de arquivos em formato de som”.

$\mathrm{Na}$ turma analisada, mesmo com 48 integrantes, houve possibilidade de diálogos e interações significativos, fazendo uso de debates, buscas virtuais, testes conceituais e outras formas de sociabilidade e investigação. Como já afirmado anteriormente (MOCARZEL; RANGEL, 2018), a didática deve, antes de tudo, estar 
a serviço do que Santos (2009, p. 269) chama de "relações emancipatórias", afinal não existe emancipação pura; esta é sempre relacional a alguma forma de poder.

No contexto universitário, falar em relações emancipatórias é falar na defesa da democracia, na valorização da cidadania, no respeito à diversidade, no combate às desigualdades socioculturais, na alfabetização política e na formação para o trabalho. A tecnologia por si só, não é solução de nenhum problema estrutural. Ela deve compor toda uma nova sociabilidade, em que os docentes se deslocam para o papel de mediação e buscam soluções para os desafios de aprendizagem para e com os alunos. Neste novo paradigma, a tecnologia, se utilizada criticamente, pode contribuir para melhorar a aprendizagem e o ensino e, consequentemente, transformar a sociedade.

\section{Referências}

BERGMANN, J.; SANS, A. Sala de aula invertida: uma metodologia ativa de aprendizagem. Rio de Janeiro: LTC, 2018.

BOTTENTUIT JUNIOR, J. B.; LISBÔA, E. S.; COUTINHO, C. P. Google Educacional: utilizando ferramentas Web 2.0 em sala de aula. Revista Educaonline, n. 1, p. 17-43, 2011.

BOURDIEU, P. A distinção: crítica social do julgamento. Porto Alegre: Zouk, 2013.

CANDAU, V. (Org.). A didática em questão. Petrópolis, RJ: Vozes, 2013.

DODGE, B. WebQuests: a technique for internet-based learning. Distance educator, n. 2, p. 10-13, 1995.

FERNANDES, D. Avaliar para aprender: fundamentos, práticas e políticas. São Paulo: Editora UNESP, 2009.

FREIRE, P. Pedagogia da autonomia. Rio de Janeiro: Paz e Terra, 1996.

GARDNER, H. Frames of mind: the theory of multiple intelligences. New York: Basic Books, 1985.

MAZUR, E. Peer instruction: a user's manual. Upper Saddle River, NJ: Pearson Prentice Hall, 1997.

MOCARZEL, M.; RANGEL, M. Por uma nova didática: experiências de educação e tecnologia no Centro Universitário La Salle do Rio de Janeiro. In: CONGRESSO INTERNACIONAL TIC E EDUCAÇÃO, 5., 2018, Lisboa. Atas... Lisboa: [s.n.], 2018. Disponível em: http://ticeduca.ie.ul.pt/atas/atas_te_2018.pdf Acesso em 10 jun. 2020.

ORLANDI, E. Análise de discurso: princípios e procedimentos. Campinas, SP: Pontes Editores, 2010. 
PÊCHEUX, M. Análise de discurso. Campinas, SP: Pontes, 2011.

PENIN, S. T. S. Didática e cultura: o ensino comprometido com o social e a contemporaneidade. In: CASTRO, A. D.; CARVALHO, A. M. P. (Org.). Ensinar a ensinar: didática para a escola fundamental e média. São Paulo: Thomson Learning, 2002. p. 33-52.

PÉREZ GÓMEZ, A. I. A cultura escolar na sociedade neoliberal. Porto Alegre: Artmed, 2001.

RANGEL, M. Métodos de ensino para a aprendizagem e a dinamização das aulas. Campinas, SP: Papirus Editora, 2010.

SACRISTÁN, J. G.; PÉREZ GÓMEZ, A. I. Compreender e transformar o ensino. Porto Alegre: Artmed, 2007.

SANTOS, B. S. A crítica da razão indolente: contra o desperdício da experiência. São Paulo: Cortez, 2009.

SARTRE, J. P. Ser e nada. Petrópolis, RJ: Vozes, 2002.

ZABALA, A. A prática educativa: como ensinar. Porto Alegre: Artmed, 2010.

RECEBIDO: $18 / 04 / 2020$

APROVADO: 25/05/2021
RECEIVED: 04/18/2020

APPROVED: 05/25/2021
RECIBIDO: $18 / 04 / 2020$

APROBADO: 25/05/2021 